\title{
Preclinical antitumor activity of SST0116CL1: A novel heat shock protein 90 inhibitor
}

\author{
LOREDANA VESCI, FERDINANDO MARIA MILAZZO, VALERIA CAROLLO, \\ SILVIA PACE and GIUSEPPE GIANNINI
}

Research \& Development, Sigma-Tau Industrie Farmaceutiche Riunite S.p.A., Pomezia, Italy

Received May 15, 2014; Accepted July 2, 2014

DOI: 10.3892/ijo.2014.2575

\begin{abstract}
Amino substituted resorcino-isoxazole (SST0116CL1) (property of Sigma-Tau Research Switzerland S.A.) is a potent, second generation, small-molecule heat shock protein 90 inhibitor (Hsp90i). SST0116CL1 binds to the ATP binding pocket of Hsp90, and interferes with Hsp90 chaperone function thus resulting in client protein degradation and tumor growth inhibition. The aim of the study was to assess SST0116CL1 in various solid and haematological tumors. The antitumor properties of SST0116CL1 were assessed using in vitro cell proliferation and client protein degradation assays and in vivo different tumor xenograft models. Pharmacokinetic (PK) data were also generated in tumor-bearing mice to gain an understanding of optimal dosing schedules and regimens. SST0116CL1 was shown to inhibit recombinant Hsp90 $\alpha$ and to induce the destabilization of different client proteins, often overexpressed and constitutively activated in different types of hematological or solid human tumors. In preclinical in vivo studies, it was revealed to induce antitumor effects in murine models of leukemia and of gastric and ovarian carcinoma. A modulation of PD biomarkers in terms of downregulation of Hsp90 client proteins in tumor-bearing mice was found. SST0116CL1 is a new clinical candidate for cancer therapy. The antitumor property of SST0116CL1, likely due to direct inhibition of the Hsp90 enzymatic activity, may prove to be a critical attribute as the compound enters phase I clinical trials.
\end{abstract}

\section{Introduction}

Heat shock protein 90 (Hsp90) is a molecular chaperone that contributes to the maintenance of the correct folding of critical protein effectors involved in cell survival, growth and differentiation (1). Hsp90, in association with other cochaperone proteins,

Correspondence to: Dr Loredana Vesci, Biotechnology, R\&D, Sigma-Tau Industrie Farmaceutiche Riunite S.p.A., Via Pontina, Km. 30.400, I-00040 Pomezia, Italy

E-mail: loredana.vesci@sigma-tau.it

Key words: heat shock protein 90, antitumor, client proteins catalyzes via its ATPase activity the conformational changes of client proteins, that are mainly involved in cell signalling, proliferation and survival (2). In addition, Hsp90 ensures the stability of a number of mutated client proteins required for tumor growth and resistance (3). In recent years this molecular target has gained considerable interest for the discovery and development of novel anticancer drugs $(4,5)$, because of their putative therapeutic use in multiple cancer indications.

Thus, a number of novel synthetic Hsp90 inhibitors, such as NVP-AUY922 (Novartis/Vernalis) (6), STA-9090 (Synta) (7), AT13387 (Astex) delivered intravenously and XL-888 (Exelixis), DS-2248 and Debio 0932 orally administered (8), are currently under oncology clinical investigations. Besides having the unusual ability of disrupting the activity of many receptors, kinases and transcription factors, all these drugs overcome the potential limitations of the ansamycin-derived Hsp90 inhibitors including complex formulations, poor solubility and hepatotoxicity (8).

Preclinical data in human tumor xenograft models show that these Hsp90 inhibitors are efficacious in a wide variety of tumor types, through activity against different oncoproteins (9). Antitumor efficacy ranges from minimal effects to tumor growth stasis, but rarely leads to tumor regression (10-15). The different efficacy of antitumor response in various xenograft models may be attributable to differences in client protein dependence on Hsp90, tumor dependence on the client protein, kinetics of client protein degradation and turnover, as well as drug pharmacokinetic and pharmacologic properties. This complexity makes it difficult to predict antitumor response in xenograft models and renders patient stratification in the clinic challenging (3). Since Hsp90 also plays a key role in regulating protein function and stability in normal cells (16), the balancing of efficacy and toxicity is important to achieve as suitable therapeutic index in patients.

We have previously described the discovery of a novel series of 3,4-isoxazolediamides based Hsp90 inhibitors which were shown to have a very interesting activity both in vitro and in vivo (17). In particular, within this group, we selected the compound SST0116CL1 as a synthetic, new chemical entity designed to potently inhibit Hsp90. SST0116CL1 binds to the ATP binding pocket of Hsp90, and interferes with Hsp90 chaperone function thus resulting in client protein degradation and tumor growth inhibition. 
We report on the in vitro activity and in vivo pharmacokinetic and efficacy profiles of SST0116CL1 in human cancer cell lines from different etiology. These results support the selection of SST0116CL1 for clinical development.

\section{Materials and methods}

Compound preparation. For in vitro experiments, stock solutions of SST0116CL1 (property of Sigma-Tau Research Switzerland S.A) (see Fig. 1) were prepared in $100 \%$ dimethyl sulfoxide (DMSO) at $10 \mathrm{mM}$ and stored at $-20^{\circ} \mathrm{C}$. For intraperitoneal or intravenous administration, SST0116CL1 was formulated in $2.5 \%$ ethanol, $20 \% 50 \mathrm{mM}$ tartaric acid, $77.5 \%$ (5\% glucose in water containing $1 \%$ Tween-80) vol/vol and delivered in a volume of $10 \mathrm{ml} / \mathrm{kg}$.

Binding on Hsp90 by a fluorescence polarization assay. GM-FITC, supplied by Invivogen (cat. no. 06C23-MT, San Diego, CA, USA), was previously dissolved in DMSO to obtain $10 \mathrm{mM}$ stock solutions and kept at $-20^{\circ} \mathrm{C}$ until use. Recombinant human Hsp90, purchased from Stressgen (cat. no. SPP-776, Victoria, BC, Canada), was previously dissolved in assay buffer (HFB) to form $2.2 \mu \mathrm{M}$ stock solutions and kept at $-80^{\circ} \mathrm{C}$ until use. On the day of the experiment, compound solutions at various concentrations were prepared by serial dilutions in assay buffer (HFB) containing $20 \mathrm{mM}$ HEPES $\left(\mathrm{K}^{+}\right), \mathrm{pH} 7.3,50 \mathrm{mM} \mathrm{KCl}, 5 \mathrm{mM} \mathrm{MgCl}{ }_{2}, 20 \mathrm{mM}$ $\mathrm{Na}_{2} \mathrm{MoO}_{4}$, and $0.01 \%$ NP-40. Before each use, $0.1 \mathrm{mg} / \mathrm{ml}$ bovine $\gamma$-globulin and $2 \mathrm{mM}$ DTT were added. Fluorescence polarization (FP) was performed in Opti-Plate-96F well plates (Perkin-Elmer, Zaventem, Belgium) using the Wallac Envision 2101 multilabel plate reader (Perkin-Elmer). To evaluate the binding affinity of the molecule, $50 \mu \mathrm{l}$ of the GM-FTC solution $(5 \mathrm{nM})$ were added to $30 \mathrm{nM}$ Hsp90 in the presence of $5 \mu \mathrm{l}$ of the test compounds at increasing concentrations. The plates were shaken at $4^{\circ} \mathrm{C}$ for $4 \mathrm{~h}$, and the $\mathrm{FP}$ values in $\mathrm{mP}$ (millipolarization units) were then recorded. The $\mathrm{IC}_{50}$ value was calculated as the inhibitor concentration that displaced $50 \%$ of the tracer, each data point being the result of the average of triplicate wells, and was determined from a plot using non-linear least-squares analysis. Curve fitting was performed using Prism GraphPad software program (GraphPad Software, Inc., San Diego, CA, USA).

Cell lines and cell sensitivity to drug. A non-small cell lung carcinoma (NSCLC, NCI-H460) cell line, a breast carcinoma (BT-474) cell line, a fibrosarcoma (HT-1080) cell line and an acute monocytic leukemia (MV4;11) cell line were purchased from the American Type Culture Collection (Manassas, VA, USA). The sensitive ovarian carcinoma cell line (A2780) was from European Collection of Animal Cell Cultures (ECACC). The gastric carcinoma (GTL-16) and the epidermoid carcinoma (A431) cell lines were kindly provided by Metheresis and by Istituto Tumori di Milano, respectively. The NSCLC, the breast carcinoma and the epidermoid carcinoma cells, as well as the acute monocytic leukaemia and the ovarian carcinoma cells were grown in RPMI-1640 (Lonza, Verviers, Belgium) supplemented with $10 \%$ fetal bovine serum (FBS, Invitrogen, Geithersburg, MD, USA). The gastric carcinoma GTL-16 cells were grown in DMEM

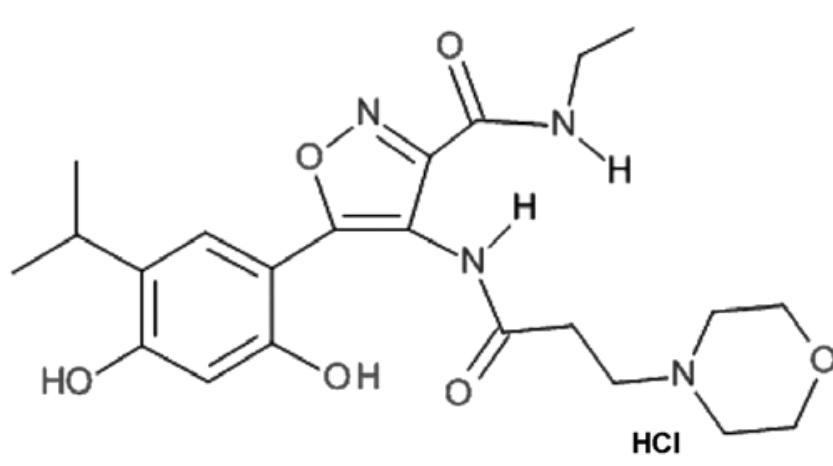

Figure 1. Chemical structure of SST0116CL1.

(Lonza) supplemented with 10\% fetal bovine serum (FBS, Invitrogen). The fibrosarcoma cells were grown in EMEM (Lonza) supplemented with 10\% fetal bovine serum (FBS, Invitrogen). Cells were routinely maintained in a humidified atmosphere with $5 \% \mathrm{CO}_{2}$ at $37^{\circ} \mathrm{C}$. All experiments were performed starting from frozen cell stocks of each cell line. When thawed, such cells were characterized in house, by assessing cell morphology, cell growth kinetics curve and absence of mycoplasma. The cell sensitivity to the drug was measured in vitro by assessing the inhibition of proliferation by sulphorodamine B (SRB) assay. Briefly, cells were seeded in 96-well tissue culture plates in complete medium (10\% FBS), and $24 \mathrm{~h}$ after seeding were treated for $72 \mathrm{~h}$ with various concentrations of SST0116CL1. The drug cytotoxic potency was evaluated by means of the 'ALLFIT' computer program and defined as $\mathrm{IC}_{50}$ (drug concentration required for $50 \%$ inhibition of cell survival).

Her2 degradation assay. BT- 474 cells were seeded into Viewplates-384TC (cat. 6007480, Perkin-Elmer Inc., Waltham, MA, USA) at the density of $2 \times 10^{4}$ cells/well in $100 \mu \mathrm{l}$ of culture medium, and were then incubated at $37^{\circ} \mathrm{C}$, in the presence of $5 \% \mathrm{CO}_{2}$ for $24 \mathrm{~h}$. Different concentrations of the drug or vehicle (DMSO) were then added to each well, and cells were cultured for further $24 \mathrm{~h}$. After washing the cells with PBS, $30 \mu 1$ of Her 2 AlphaLISA Immunoassay buffer were added to wells and mixed on a shaker at $22^{\circ} \mathrm{C}$ for $30 \mathrm{~min}$. Then $15 \mu \mathrm{l}$ of a solution $(10 \mu \mathrm{g} / \mathrm{ml})$ consisting in Her2 AlphaELISA Anti-ERBB2/Her2 Acceptor beads and $(1 \mathrm{nM})$ Biotinylated Anti-ERBB2/Her2 Antibody were added to wells, and incubated at $22^{\circ} \mathrm{C}$ for $2 \mathrm{~h}$. Finally, $5 \mu \mathrm{l}$ of $(40 \mu \mathrm{g} /$ $\mathrm{ml}$ ) Streptavidin Donor beads were added, and the plate was incubated at $22^{\circ} \mathrm{C}$ for $1 \mathrm{~h}$, in the dark, and measurements were done through the multilabel reader Envision (Wallac Envision 2101 multilabel reader, Perkin-Elmer, Zaventem, Belgium). To rule out that the declining signal in drug-treated cells was not the result of reduced cell number caused by unspecific cell death but due to decreased Her2 content, suitable viability studies were performed by means of the luminescence ATP detection assay system (ATPlite 1 Step cat. 6016941, Perkin-Elmer, Zaventem, Belgium). $\mathrm{IC}_{50}$ was calculated as the drug concentration needed to degrade $50 \%$ of the total Her2; each data point was the result of the average of triplicate wells, and determined from a plot using nonlinear 
least-squares analysis. Curve fitting was performed using the Prism GraphPad software program (GraphPad software, Inc., San Diego, CA, USA).

Western blot analysis. For the in vitro experiments, A431 (human epidermoid carcinoma) cells were seeded at $1 \times 10^{6}$ cells/100 mm dish in complete culture medium, and allowed to grow overnight at $37^{\circ} \mathrm{C}$ with $95 \%$ air and $5 \% \mathrm{CO}_{2}$. The day after, the medium was renewed and cells were treated, for $24 \mathrm{~h}$, with various concentrations of SST0116CL1. 17-DMAG (at the concentration of $0.2 \mu \mathrm{M}$ ) was used as internal reference inhibitor. Following treatments, cells were rinsed twice with ice-cold PBS and then lysed in RIPA buffer supplemented with protease and phosphatase inhibitors. After determination of the protein concentration by Bradford Protein Assay (Thermo Scientific, Rockford, IL, USA), equal amounts of cellular extracts were separated by SDS-PAGE and then transferred onto nitrocellulose membranes. Non-specific binding sites were blocked by incubation of the membranes with $5 \%$ non-fat dry milk in TBS, overnight at $4^{\circ} \mathrm{C}$. Membranes were finally probed with the following primary antibodies: anti-EGFR (Upstate Biotechnology, Millipore Corporate, Billerica, MA, USA); anti-Cdk4 (Santa Cruz Biotechnology Inc., Santa Cruz, CA, USA); anti-Akt (Cell Signaling Technology, Inc., MA, USA); anti-HSP70 (BRM-22) and anti-Actin (Sigma Chemical Co., St. Louis, MO, USA). After extensive washings in TBS, immunoreactive bands were revealed by horseradish peroxidase-conjugated secondary antibodies, using an enhanced chemiluminescence detection reagent (ECL Plus, GE Healthcare Bio-Sciences, Uppsala, Sweden), and acquired by a phosphoimaging system (STORM 860; Molecular Dynamics, Sunnyvale, CA, USA). Protein loading equivalence was corrected in relation to the expression of actin. For quantification of signals, blots were subjected to densitometry analysis.

Murine xenograft model. All experiments were carried out at Sigma-Tau (Rome, Italy) using 5-6 week-old female athymic nude mice (Harlan, Italy). Mice were maintained in laminar flow rooms with constant temperature and humidity. Experimental protocols were approved by the Ethics Committee for Animal Experimentation of Sigma-Tau according to the United Kingdom Coordinating Committee on Cancer Research Guidelines. The following human tumor xenograft models were used for antitumor activity studies: GTL-16 gastric carcinoma, MV4;11 AML, A2780/ADR multi-drug resistant ovarian carcinoma. Exponentially growing tumor cells $\left(5 \times 10^{6} /\right.$ mouse) were s.c. inoculated in the right flank of nude mice. Groups of eight mice were employed to assess antitumor activity. Drug treatments were started 3 or 4 days after tumor injection. SST0116CL1 was delivered intraperitoneally or intravenously in a volume of $10 \mathrm{ml} / \mathrm{kg}$ according to different schedules (qdx5/w: daily from Monday to Friday; q2d/w: Monday, Wednesday, Friday; q4d/w: Monday and Friday). Tumor growth was followed by measurement of tumor diameters with a Vernier caliper. Tumor volume (TV) was calculated using the formula: TV $\left(\mathrm{mm}^{3}\right)=\left[\mathrm{d}^{2} \mathrm{x} \mathrm{D}\right] / 2$, where $\mathrm{d}$ and $\mathrm{D}$ are the shortest and the longest diameter, respectively. The efficacy of the drug treatment was assessed as: TV inhibition percentage (TVI\%) in treated vs. control mice, calculated as: TVI\% $=100-[($ mean TV treated/mean TV control) x100)]. CR (complete response) was defined as no evidence of tumor at the end of the drugtreatment. When tumors reached a maximum volume of $2,000 \mathrm{~mm}^{3}$, mice were sacrificed by cervical dislocation. To examine the possible toxicity of treatment, body weight was recorded throughout the study. BWL\% (body weight loss) was calculated as $100-\left[\left(\right.\right.$ mean $\mathrm{BW}_{\text {dayx }} /$ mean $\left.\left.\left.\mathrm{BW}_{\text {dayl }}\right)\right] \mathrm{x} 100\right)$, where day 1 is the first day of treatment and day $\mathrm{x}$ is any day after (maximum BWL\%). In order to assess the in vivo effect of SST0116CL1 on the expression of typical HSP90 client proteins, GTL-16 tumor xenografts (4 samples/group) were excised at different times after the last treatment, and then total protein lysates were prepared through the homogenization of tumor samples in T-PER (Tissue Protein Extraction Reagent, Pierce, Rockland, IL, USA), supplemented with $10 \mu \mathrm{g} / \mathrm{ml}$ of protease inhibitor cocktail (Sigma Chemical Co., St. Louis, MO, USA). Determination of the protein concentration and western blot analysis were finally performed as previously described for the in vitro experiments.

PK sampling and analysis. CD1 nude mice bearing A431 epidermoid carcinoma xenografts were used. Mice were treated with a single intraperitoneal dose of SST0116CL1 at $80 \mathrm{mg} / 10 \mathrm{ml} / \mathrm{kg}$. Levels of SST0116CL1 were determined in blood, lung and tumor samples collected at 1,2, 4, 8 and $24 \mathrm{~h}$ post-treatment. Bioanalysis was conducted by quantitative HPLC-MS/MS and PK analysis was carried out according to a non-compartmental approach for sparse data sampling (WinNonLin, Pharsight). The maximum plasma concentration $\left(\mathrm{C}_{\max }\right)$ of SST0116, and the corresponding times of occurrence $\left(\mathrm{T}_{\max }\right)$ were obtained directly from the mean plasma or tissue concentration data. The slope of the terminal disposition phase $(\mathrm{k})$ was determined by logarithmic-linear regression and used to calculate the terminal half-life $\left(\mathrm{T}_{1 / 2}\right)$ as $0.693 / \mathrm{k}$. The linear trapezoidal rule was used to estimate the area under the plasma concentration versus time curve from zero to the last time point with a measurable drug concentration $\left(\mathrm{C}_{\text {last }}\right)$ for $\mathrm{AUC}_{0 \text {-last }}$, and extrapolating to infinity by addition of the quantity $\mathrm{C}_{\text {last }} / \mathrm{k}$ for $\mathrm{AUC}_{0 \text {-inf. }}$ The apparent total clearance, $(\mathrm{CL} / \mathrm{F})$ and the apparent terminal volume of distribution $(\mathrm{Vz} / \mathrm{F})$ referenced to plasma were calculated as \left.${\text { Dose } / \mathrm{AUC}_{0 \text {-inf }} \text {, and Dose/(k*AUC }}_{0 \text {-inf }}\right)$, respectively.

Statistical analysis. The data shown represent mean values \pm standard error of mean (SEM) and standard deviation (SD). For comparison between a control and a treatment group, an unpaired Mann-Whitney test was used. A P-value $\leq 0.05$ was considered significant.

\section{Results}

SST0116CL1 inhibits cell growth, and recombinant HSP90 $\alpha$. In a competitive binding fluorescence polarization assay, SST0116CL1 was shown to inhibit recombinant Hsp90 $\alpha$, with an $\mathrm{IC}_{50}$ value of $0.2 \mu \mathrm{M}$ (Table I). The ability of SST0116CL1 to induce degradation of Her2 in BT-474 human breast carcinoma cells, was also measured by means of a specific Her2 AlphaELISA immunoassay. As shown in Table I, exposure of BT-474 cells for $24 \mathrm{~h}$ to increasing concentra- 
Table I. Binding affinity to recombinant human HSP90 $\alpha$ and Her2 degradation on BT474 breast carcinoma cells.

\begin{tabular}{lcc}
\hline Compound & $\begin{array}{c}\mathrm{HSP} 90 \alpha \\
\left(\mathrm{IC}_{50} \pm \mathrm{SD}, \mu \mathrm{M}\right)\end{array}$ & $\begin{array}{c}\text { Her2 } \\
\left(\mathrm{IC}_{50} \pm \mathrm{SD}, \mu \mathrm{M}\right)\end{array}$ \\
\hline SST0116CL1 & $0.21 \pm 0.03$ & $0.20 \pm 0.02$ \\
\hline
\end{tabular}

Competitive binding fluorescence polarization assay and Her2 AlphaLISA Immunoassay were used as described in Materials and methods. $\mathrm{IC}_{50}$ values were the average of at least three independent determinations.

tions of SST0116CL1 was able to cause a significant reduction in cellular levels of Her2, with an $\mathrm{IC}_{50}$ value of $0.2 \mu \mathrm{M}$. The ability of SST0116CL1 to target Hsp90 directly on human tumor cells was evaluated by a tumor cell proliferation assay against a representative panel of human tumor cell lines, including fibrosarcoma (HT-1080), acute monocytic leukemia (MV4;11), NSCLC (NCI-H460), ovarian (A2780), epidermoid (A431), gastric (GTL-16), breast (BT-474) carcinoma cell lines, characterized by constitutively activated oncogenic pathways (Table II). SST0116CL1 was effective in inhibiting cell growth in all the different tumor cell lines, following 72-h exposure, with $\mathrm{IC}_{50}$ values ranging from 0.1 to $0.8 \mu \mathrm{M}$ (Table II). Because the broad mechanism of action of SST0116CL1, such as for other Hsp90 inhibitors, it was not possible to associate the sensitivity observed in the cell panel with the mutation of a single gene. These results correlated well with those obtained from the Her2 degradation assay as well as with the Hsp90 competitive binding assay.

SST0116CL1 inhibits the expression of specific Hsp90 client proteins. The ability of SST0116CL1 to downregulate the expression of a few representative Hsp90 protein clients and to induce the expression of Hsp70 protein was assessed, by western blot analysis, in the A431 human squamous carcinoma cell line, characterized by the constitutive overexpression of EGFR. As shown in Fig. 2, a dramatic depletion of selected Hsp90 client proteins (EGFR, CDK4 and AKT), associated to a very strong increase in the expression levels of Hsp70, was achieved in A431 cells after a 24-h exposure of cells even to concentrations of SST0116 almost 10-fold lower than the cytotoxic doses of the drug. Thus, the modulation of client proteins and the upregulation of Hsp70 cochaperone were consistent with inhibition of Hsp90 function, and confirmed that target modulation of Hsp90 was achieved.

SST0116CL1 inhibits tumor growth in different cancer cell xenografts. SST0116CL1 significantly reduced solid tumor growth in different xenograft models. Against the gastric carcinoma (GTL-16), SST0116CL1, administered at $90 \mathrm{mg} / 10 \mathrm{ml} / \mathrm{kg}$ i.p. according to the schedule qdx5/wx3w, was able to induce a significantly Tumor Volume Inhibition of $61 \%$ ( $\mathrm{P}<0.001$; Fig. 3A). Interestingly, the compound revealed to be well-tolerated and to protect mice from cachexia induced by this tumor xenograft (see the body weight of treated group in comparison with the drug-treated group) (Fig. 3B). To validate that the in vivo antitumor effect of SST0116CL1 was effectively related to the inhibition of Hsp90, the modulation of selected Hsp90 client proteins was assessed by western blot in tumor xenografts a few hours after the last treatment. As shown in Fig. 3C, SST0116CL1 induced a relevant decrease of the protein levels of three typical client proteins (c-MET, AKT and CDK4) in GTL-16 tumor lysates and, at the same time, significantly increased the expression levels of the chaperone Hsp70, thus confirming that inhibition of Hsp90 function was achieved. The in vivo antitumor efficacy of SST0116CL1 against MV4;11 AML cell line was also investigated. Administration of SST0116CL1 $(200 \mathrm{mg} / 10 \mathrm{ml} /$ $\mathrm{kg}$ ) intravenously (q4d/wx2w) and $(200 \mathrm{mg} / 10 \mathrm{ml} / \mathrm{kg})$ intraperitoneally (q2d/wx2w) showed a very potent antitumor effect $(\mathrm{TVI}=90 \%, \mathrm{P}<0.001$, with $50 \%$ of complete response, and $\mathrm{TVI}=81 \%, \mathrm{P}<0.01$, with $22 \%$ of complete response, respectively) (Fig. 4A). Thus, the antitumor efficacy was comparable irrespectively of the routes and schedules. In both treatments, SST0116CL1 was revealed to be well tolerated. The A2780/Dx ovarian tumor cell line, overexpressing P-glycoprotein, also showed a significant responsiveness to the compound (TVI=71\%, $\mathrm{P}<0.01$ ). Against this tumor model, SST0116CL1 was delivered at $200 \mathrm{mg} / 10 \mathrm{ml} / \mathrm{kg}$ i.p.

Table II. Antiproliferative activity of SST0116CL1 on different tumor cell lines.

\begin{tabular}{llcl}
\hline Cell line & \multicolumn{1}{c}{ Tissue } & $\begin{array}{c}\text { SST0116CL1 } \\
\mathrm{IC}_{50} \pm \mathrm{SD}(\mu \mathrm{M})\end{array}$ & $\begin{array}{c}\text { Alterated } \\
\text { oncogenic pathway }\end{array}$ \\
\hline A431 & Epidermoid carcinoma & $0.81 \pm 0.02$ & EGFR \\
NCI-H460 & NSCLC & $0.11 \pm 0.1$ & KRAS \\
A2780 & Ovarian carcinoma & $0.81 \pm 0.1$ & PTEN \\
MV4;11 & Acute monocytic leukemia & $0.40 \pm 0.07$ & FLT3 \\
GTL-16 & Gastric carcinoma & $0.23 \pm 0.04$ & MET \\
BT474 & Breast carcinoma & $0.62 \pm 0.1$ & HER2 \\
HT-1080 & Fibrosarcoma & $0.34 \pm 0.09$ & NRAS \\
\hline
\end{tabular}

Tumor cells were treated for $72 \mathrm{~h}$ with different concentrations of SST0116CL1 as described in Materials and methods. Results are expressed as average $\mathrm{IC}_{50}$ values $( \pm \mathrm{SD})$ for three independent experiments. 

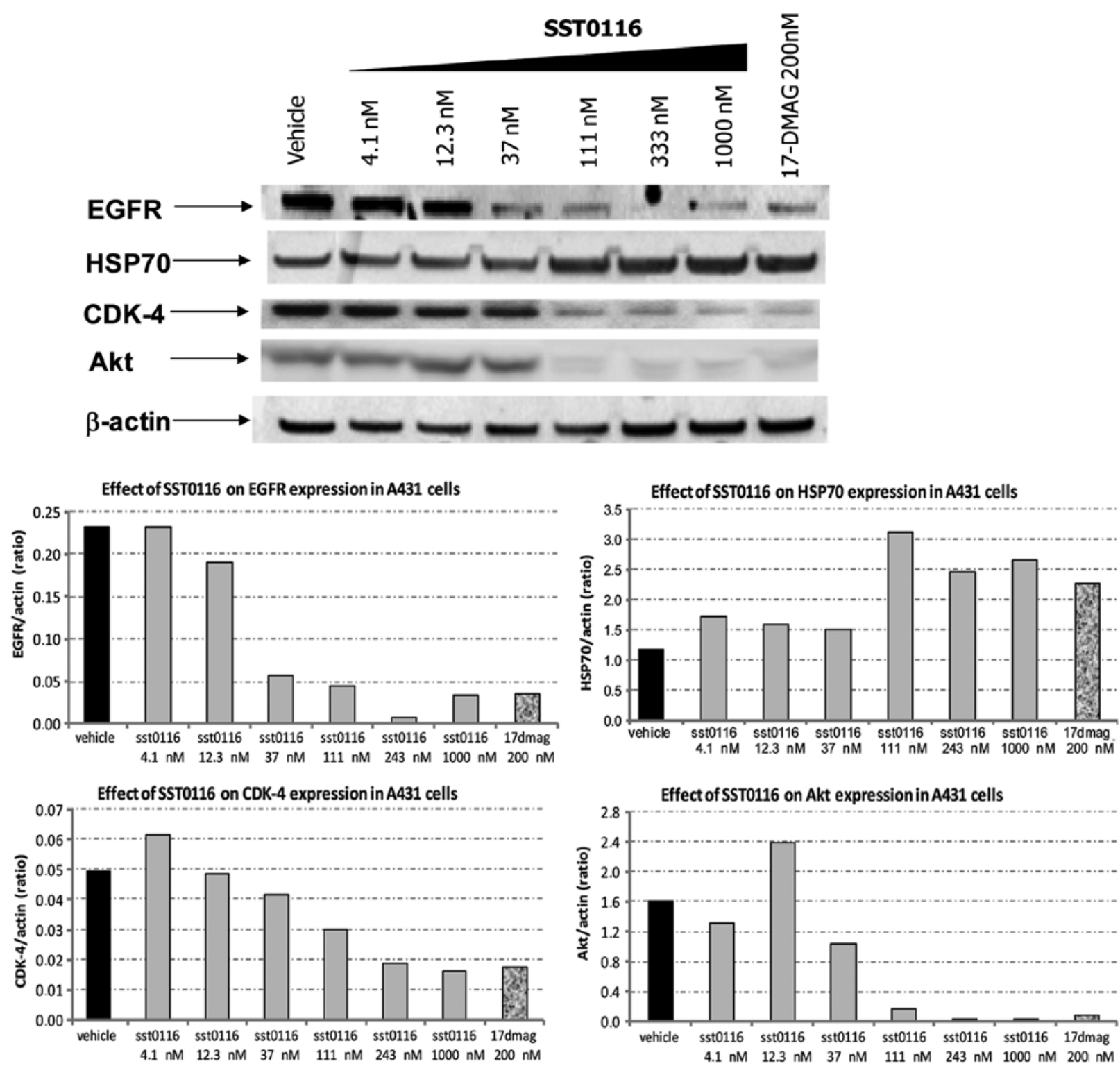

Figure 2. SST0116CL1 downregulates Hsp90 client protein levels (EGFR, Akt, CDK-4) and upregulates Hsp70 in A431 epidermoid carcinoma cells. Total cellular extracts were obtained $24 \mathrm{~h}$ after treatment. 17-DMAG was used as positive internal reference. Actin is shown as a control for protein loading. A representative blot is shown. Results of densitometry analysis were reported as normalized (to actin) ratios. Western blot experiments were performed at least twice resulting in very similar results.

Table III. Model independent pharmacokinetic analysis of SST0116CL1 in the plasma and tissues of tumor-bearing mice (A431 epidermoid carcinoma).

\begin{tabular}{lccccccc}
\hline Tissue & $\begin{array}{c}\mathrm{T}_{\max } \\
(\mathrm{h})\end{array}$ & $\begin{array}{c}\mathrm{C}_{\max } \\
(\mathrm{ng} / \mathrm{ml})\end{array}$ & $\begin{array}{c}\mathrm{AUC}_{\text {last }} \\
(\mathrm{h} * \mathrm{ng} / \mathrm{ml})\end{array}$ & $\begin{array}{c}\text { HL_Lambda_z } \\
(\mathrm{h})\end{array}$ & $\begin{array}{c}\text { CL_F_obs } \\
(\mathrm{ml} / \mathrm{h} / \mathrm{kg})\end{array}$ & $\begin{array}{c}\text { AUCinf_obs } \\
(\mathrm{h} * \mathrm{ng} / \mathrm{ml})\end{array}$ & $\begin{array}{c}\text { Vz_F_obs } \\
(\mathrm{ml} / \mathrm{kg})\end{array}$ \\
\hline Plasma & 1.00 & 2,953 & 6,822 & 5.8 & 11,268 & 7,100 & 94,551 \\
Lung & 1.00 & 4,890 & 21,676 & 6.5 & & 23,287 & \\
Tumor & 2.00 & 4,046 & 54,387 & $\mathrm{NE}$ & & 267,987 & \\
\hline
\end{tabular}

AUC, area under the concentration vs. time curve.

according to the schedule $\mathrm{q} 4 \mathrm{~d} / \mathrm{wx} 3 \mathrm{w}$, and again it did not show any toxicity (Fig. 4B).
SST0116CL1 shows a preferential distribution in tumors. The PK profile of SST0116CL1 in tumor bearing animals 

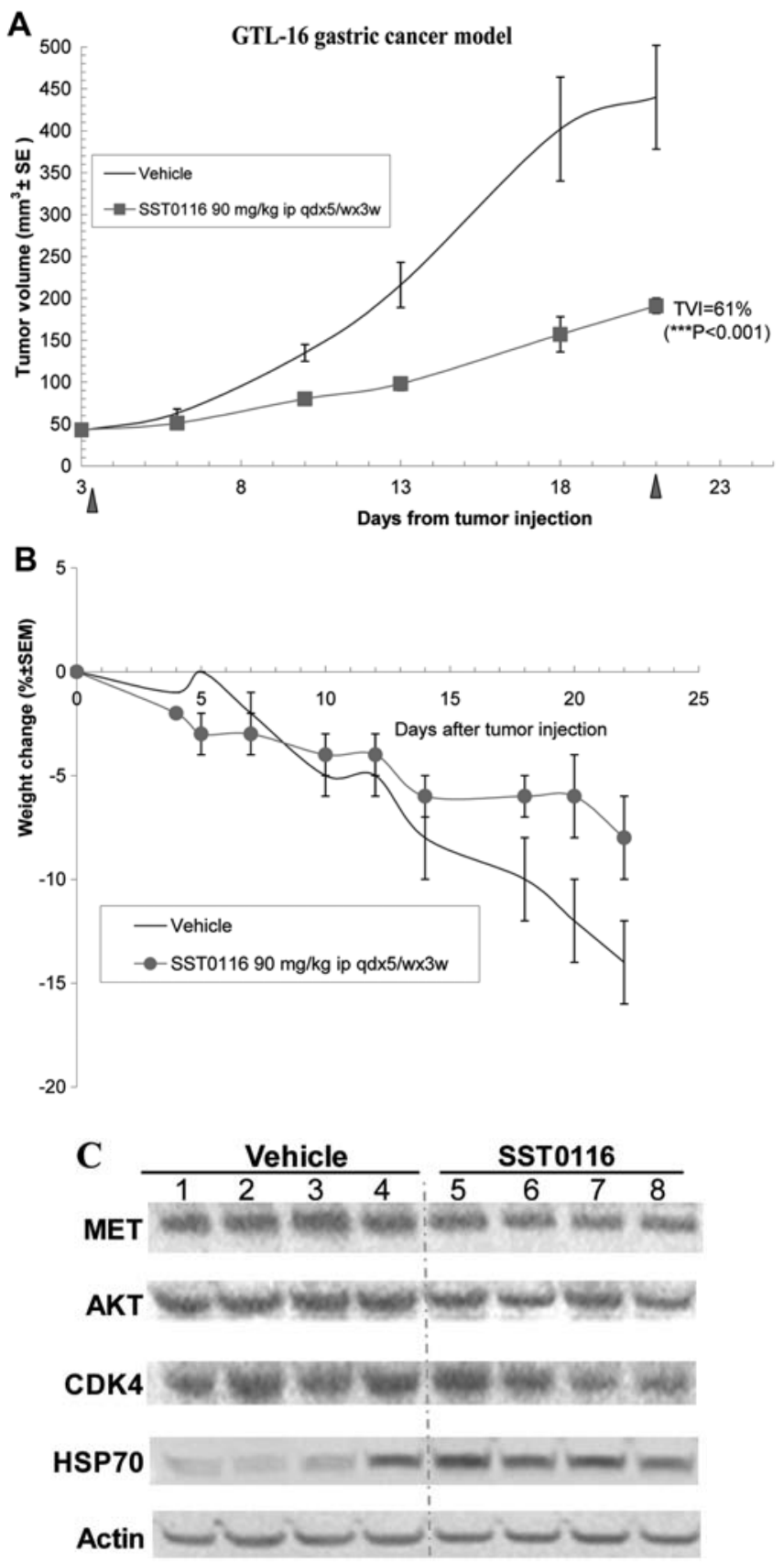

Figure 3. SST0116CL1 (90 mg/kg, i.p.; qdx5/wx3w) (A) significantly inhibits tumor progression in gastric cancer model (GTL-16) and (B) protects mice from cachexia induced by the tumor. Treatment started when tumors reached $50 \mathrm{~mm}^{3}\left({ }^{* * *} \mathrm{P}<0.001\right.$ vs. vehicle control; Mann-Whitney test; $\mathrm{n}=8$ /group). (C) SST0116CL1 (lanes 5-8) downregulates Hsp90 client protein levels (c-MET, AKT, CDK4) and upregulates Hsp70, with respect to vehicle-treated mice (lanes 1-4), in GTL-16 tumor samples collected $6 \mathrm{~h}$ after the last treatment. Actin is shown as a control for protein loading. Representative blots of four tumor samples/group are shown.

was determined after a single dose of $80 \mathrm{mg} / 10 \mathrm{ml} / \mathrm{kg}$ of compound administered intraperitoneally. The concentrations of SST0116CL1 were assessed in both blood and tissue samples (tumor and lung). $\mathrm{A} \mathrm{C}_{\max }$ of $2,953 \mathrm{ng} / \mathrm{ml}$ was observed in plasma $1 \mathrm{~h}$ after dosing, then plasma concentrations decreased according to a bi-exponential profile, having a terminal half-life of $5.8 \mathrm{~h}$. As suggested by its plasma concentration versus time profile, SST0116CL1 distributed
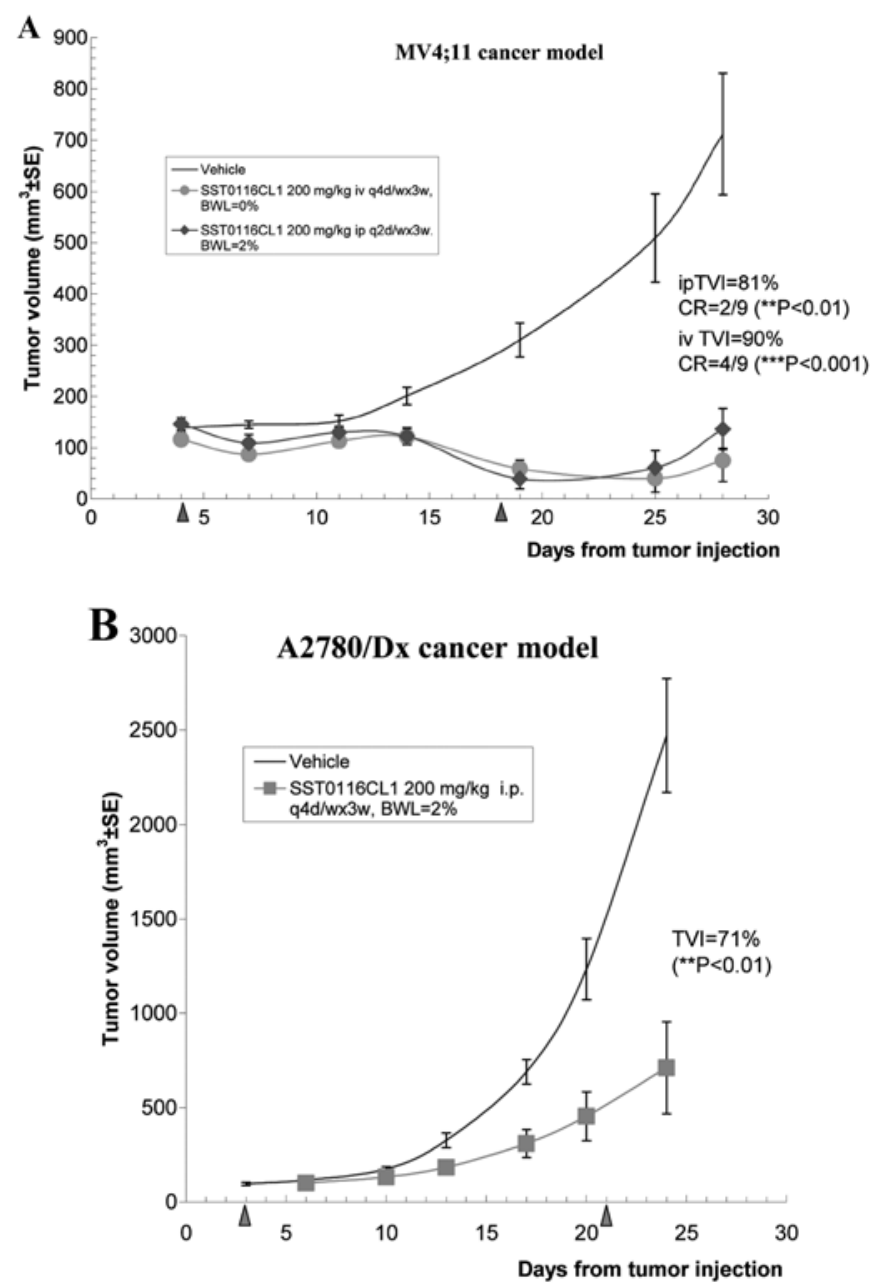

Figure 4. SST0116CL1 significantly inhibits (A) tumor progression in AML (MV4;11) and (B) multidrug-resistant ovarian carcinoma (A2780/ Dx). Body weight loss (BWL\%) was also reported. Treatment started when tumors reached $50-100 \mathrm{~mm}^{3}$. ${ }^{* * *} \mathrm{P}<0.01$ and ${ }^{* * *} \mathrm{P}<0.001$ vs. vehicle control (Mann-Whitney test, $\mathrm{n}=8$ per group].

outside the systemic circulation, reaching $\mathrm{C}_{\max }$ of $4,890 \mathrm{ng} /$ $\mathrm{ml}$ in lung and $4,046 \mathrm{ng} / \mathrm{ml}$ in tumor within 1 and $2 \mathrm{~h}$, respectively (Table III). The terminal elimination phase in lung paralleled that of plasma $\left(\mathrm{T}_{1 / 2}\right.$ of $\left.6.5 \mathrm{~h}\right)$; conversely SST0116CL1 seemed to accumulate in tumor; in fact, in this tissue its concentration declined much more slowly than in plasma and lung (Fig. 5). The tissue to plasma $\mathrm{AUC}_{0 \text {-last }}$ ratios turned out to be about 3 for lung and 8 for tumor; thus these data reveal enhanced tissue distribution. The CL/F and $\mathrm{Vz} / \mathrm{F}$ evaluated from plasma data were $11,268 \mathrm{ml} / \mathrm{h} / \mathrm{kg}$ and $94,551 \mathrm{ml} / \mathrm{kg}$, respectively. The high values of $\mathrm{CL} / \mathrm{F}$ and $\mathrm{Vz} / \mathrm{F}$ might also reflect an incomplete bioavailability of the tested compound in nude mouse.

\section{Discussion}

Hsp90 is a component of a molecular chaperone complex that plays critical roles in regulating the folding, maturation and stabilisation of key signalling molecules which control cell proliferation, survival and transformation. Hsp90 works in association with other cochaperones and catalyzes, via its 


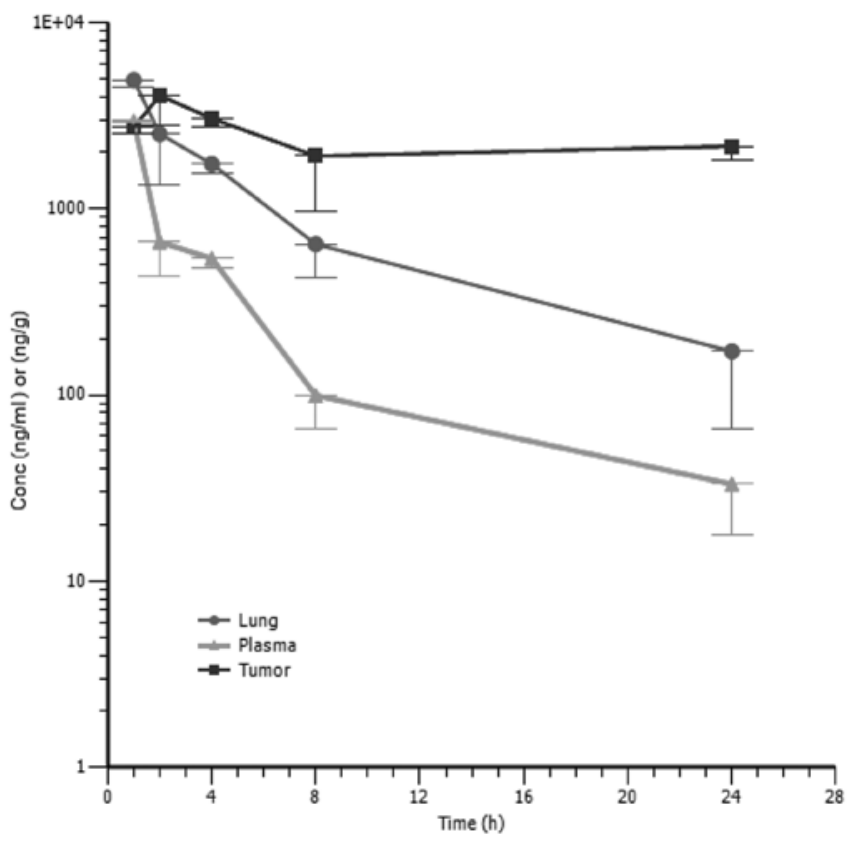

Figure 5. Plasma and tissue concentration vs. time profiles for SST0116CL1 administered as a single intraperitoneal dose of $80 \mathrm{mg} / \mathrm{kg}$ in tumor-bearing mice (A431 epidermoid carcinoma)

ATPase, the conformational changes of a set of cancer-associated proteins, collectively referred to as 'clients'. Inhibition of Hsp90 causes simultaneous destabilization and eventual degradation of client proteins that in turn result in suppression of tumor growth. A number of novel synthetic Hsp90 inhibitors are currently under oncology clinical investigations for the treatment of a wide variety of tumor types $(8,18,19)$. The earlier geldanamycin analogues (i.e., 17-AAG or 17-DMAG), despite potent in vitro and in vivo preclinical activity, have not shown clear clinical benefit $(5,20)$. The disappointing clinical activity was due to their poor selectivity, pharmaceutical properties and toxicity profiles in patients $(21,22)$. Given this precedent, we planned to identify novel Hsp90 inhibitors with a superior pharmacological and tolerability profile. We previously identified a new class of 3,4-isoxazolediamides (17), where the compound SST0116CL1 was selected as a potential new drug candidate, unrelated to the ansamycin class of natural products. We chose to investigate molecules with innovative changes and to assess the benefits of such changes through well-focused in vivo studies, based on suitable tumor models.

SST0116CL1 in the studies in vitro was shown to inhibit recombinant $\mathrm{Hsp} 90 \alpha$ and to induce the degradation of the oncogenic Her2 tyrosine kinase in BT-474 human breast cancer cells. The degradation of the oncogenic Her2 tyrosine kinase represents a biological effect observed upon addition of known Hsp90 inhibitors to cancer cells (22). Overexpression of Her 2 in cancer cells, such as breast and ovarian carcinoma cells, usually results in Akt activation which in turn promotes cell survival. Hsp90 inhibitors induce Her2 degradation through disruption of the Her2/Hsp90 association, and this effect is detrimental to the cell leading to its death (23). Moreover, SST0116CL1 was able to induce the destabilization and depletion of different client proteins, often overexpressed and constitutively activated in numerous types of hematological or solid human tumors. These results well correlated with those obtained from the cell proliferation assay as well as with the Hsp90 competitive binding assay, and clearly confirmed that target modulation of Hsp90 was achieved. We also showed a putative broad spectrum of antiproliferative activity on a panel of tumor cell lines harboring different gene mutations: K-Ras mutations (H460), EGFR and Her2 amplification (A431 and BT474, respectively), N-Ras mutation (HT1080), PTEN loss (A2780), FLT3 mutation (MV4;11) and c-met amplification (GTL-16).

Although the in vitro activity of SST0116CL1 was not particularly potent with respect to analogues Hsp90 inhibitors currently undergoing clinical trials, it showed, however, a great versatility and a good pharmacological profile when assessed in vivo for tolerability, pharmacokinetics, pharmacodynamics and antitumor activity. In some solid and haematological tumor xenograft models, SST0116CL1 delivered intravenously or intraperitoneally at different schedules, from once a day to once every two or four days (qdx5/w; q2d/w; q4d/w), in both sensitive and doxorubicin-resistant tumor models, showed a statistically significant tumor growth inhibition with a TVI ranging from 61 to $90 \%$, associated to a slight body weight loss (BWL) during the drug-treatment. Three tumor cell lines were selected as tumor xenograft models to represent a diversity of tumor types and oncogenic drivers. The GTL-16 tumor cell line was chosen because of amplification of the receptor tyrosine kinase c-Met, a client protein of Hsp90, and for its dependency on c-Met for growth and survival (24), MV4; 11 leukemia driven by the tyrosine kinase receptor FLT3ITD mutation, was also analyzed. The activating internal tandem duplications (ITD) in the juxtamembrane domain of FLT3 have been identified in 35\% AML patients (25). MV4;11 has been shown to be dependent on FLT3-ITD by its sensitivity to selective FLT3 kinase inhibitors (26). The best approach to the treatment of FLT3-ITD AML is currently undefined and multiple clinical trials are investigating inhibitors of the FLT3 kinase (27). Their action is very often transient, possibly due to inadequate dosing or insufficient selectivity of these drugs. SST0116CL1 treatment of the MV4;11 AML resulted in eradication of a good percentage of tumors after subcutaneous tumor cell implantation.

Since many types of cancer express relatively high levels of P-glycoprotein, a major type of MDR protein (28), we show that, unlike Hsp90 inhibitors such as $17-\mathrm{AAG}$ and its derivatives (29), SST0116CL1 exhibited no MDR dependency in A2780/ADR tumor xenograft model. This characteristic makes SST0116CL1 a potentially superior Hsp90 inhibitor in the situation where P-gp is expressed, enabling it, to overcome the MDR barrier that commonly undermines cancer therapy. Differently, 17-AAG could itself induce P-gp expression, rendering the drug less effective during treatment (29).

A modulation of PD biomarkers in terms of downregulation of EGFR, AKT and CDK4 client proteins was achieved either in vitro, on A431 tumor cells treated with SST0116CL1, and in terms of down-modulation of c-Met, AKT and CDK4 ex vivo in tumor lesions collected from GTL-16 tumorbearing mice. The molecular signature of Hsp90 inhibition represents a fundamental pharmacodynamic biomarker of efficacy in cancer cell lines, and has been well validated in human tumor xenografts as well as to measure target 
inhibition in cancer patients receiving treatments with selective Hsp90 inhibitors (30-32). It has been extensively demonstrated that targeting cellular Hsp90 protein function with pharmacological doses of Hsp90 inhibitors results in the depletion of the well-established client proteins, mainly represented by oncogenic proteins or, more generally, cellular proteins involved in the modulation of critical cell pathways and mechanisms, such as cell cycle, proliferation and survival, and in the upregulation of other members of the Hsp90 family. An advantage of Hsp90 inhibitors is their ability to affect multiple oncoproteins simultaneously. This is relevant given the emerging data showing resistant phenotypes arising from mutation, activation of alternative signaling pathways or feedback loops, frequently seen with therapeutics targeting a single oncogene or pathway (33). The preclinical data of tolerability, manageability and activity profile make SST0116CL1 a very attractive antitumor therapeutic agent ready to undergo clinical studies.

\section{Acknowledgements}

The authors wish to thank Dr M.B. Guglielmi, Dr M. Barbarino, Dr R. Foderà, Dr M. Castorina, Dr M.L. Cervoni, Mrs P. Tobia and Mr. A. Marconi for their excellent technical assistance. The authors declare no financial interest.

\section{References}

1. Li J and Buchner J: Structure, function, and regulation of the Hsp90 machinery. Biomed J 36: 106-117, 2013.

2. Hao H, Naomoto Y, Bao X, Watanabe N, Sakurama K, Noma K, Motoki T, Tomono Y, Fukazawa T, Shirakawa Y, Yamatsuji T, Matsuoka J and Takaoka M: Hsp90 and its inhibitors. Oncol Rep 23: 1483-1492, 2010.

3. Whitesell L and Lindquist SL: HSP90 and the chaperoning of cancer. Nat Rev Cancer 5: 761-772, 2005.

4. Mahalingam D, Swords R, Carew JS, Nawrocki ST, Bhalla K and Gilles FJ: Targeting HSP90 for cancer therapy. Br J Cancer 100: 1523-1529, 2009.

5. Kim YS, Alarcon SV, Lee S, Lee MJ, Giaccone G, Neckers L and Trepel JB: Update on Hsp90 inhibitors in clinical trial. Curr Top Med Chem 9: 1479-1492, 2009.

6. Sessa C, Shapiro GI, Bhalla KN, Britten C, Jacks KS, Mita M, Papadimitrakopoulou V, Pluard T, Samuel TA, Akimov M, Quadt C, Fernandez-Ibarra C, Lu H, Bailey S, Chica S and Banerji U: First-in-human phase I dose-escalation study of the Hsp90 inhibitor AUY922 in patients with advanced solid tumors. Clin Cancer Res 19: 3671-3680, 2013.

7. Goldman JW, Raju RN, Gordon GA, El-Hariry I, Teofilivici F, Vukovic VM, Bradley R, Karol MD, Chen Y, Guo W, Inoue T and Rosen LS: A first in human, safety, pharmacokinetics, and clinical activity phase I study of once weekly administration of the Hsp90 inhibitor ganetespib (STA-9090) in patients with solid malignancies. Biomed Central Cancer 13: 152-161, 2013.

8. Soga S, Akinaga S and Shiotsu Y: Hsp90 inhibitors as anti-cancer agents, from basic discoveries to clinical development. Curr Pharm Des 19: 366-376, 2013.

9. Li J, Soroka J and Buchner J: The Hsp90 chaperone machinery: conformational dynamics and regulation by co-chaperons. Biochim Biophys Acta 1823: 624-635, 2012.

10. Eccles SA, Massey A, Raynaud FI, Sharp SY, Box G, Valenti M, Patterson L, de Haven Brandon A, Gowan S, Boxall F, Aherne W, Rowlands M, Hayes A, Martins V, Urban F, Boxall K, Prodromou C, Pearl L, James K, Matthews TP, Cheung KM, Kalusa A, Jones K, McDonald E, Barril X, Brough PA, Cansfield JE, Dymock B, Drysdale MJ, Finch H, Howes R, Hubbard RE, Surgenor A, Webb P, Wood M, Wright L and Workman P: NVP-AUY922: a novel heat shock protein 90 inhibitor active against xenograft tumor growth, angiogenesis, and metastasis. Cancer Res 68: 2850-2860, 2008.
11. Jensen MR, Schoepfer J, Radimerski T, Massey A, Guy CT, Brueggen J, Quadt C, Buckler A, Cozens R, Drysdale MJ, Garcia-Echeverria $C$ and Chène P: NVP-AUY922: a small molecule HSP90 inhibitor with potent antitumor activity in preclinical breast cancer models. Breast Cancer Res 10: R33, 2008.

12. Wang Y, Trepel JB, Neckers LM and Giaccone G: STA-9090, a small-molecule Hsp90 inhibitor for the potential treatment of cancer. Curr Opin Investig Drugs 11: 1466-1476, 2010.

13. Okawa Y, Hideshima T, Steed P, Vallet S, Hall S, Huang K, Rice J, Barabasz A, Foley B, Ikeda H, Raje N, Kiziltepe T, Yasui H, Enatsu S and Anderson KC: SNX-2112, a selective Hsp90 inhibitor, potently inhibits tumor cell growth, angiogenesis, and osteoclastogenesis in multiple myeloma and other hematologic tumors by abrogating signaling via Akt and ERK. Blood 113: 846-855, 2009.

14. Lin TY, Bear M, Du Z, Foley KP, Ying W, Barsoum J and London C: The novel HSP90 inhibitor STA-9090 exhibits activity against Kit-dependent and -independent malignant mast cell tumors. Exp Hematol 36: 1266-1277, 2008.

15. Lundgren K, Zhang H, Brekken J, Huser N, Powell RE, Timple N, Busch DJ, Neely L, Sensintaffar JL, Yang YC, McKenzie A, Friedman J, Scannevin R, Kamal A, Hong K, Kasibhatla SR, Boehm MF and Burrows FJ: BIIB021, an orally available, fully synthetic small-molecule inhibitor of the heat shock protein Hsp90. Mol Cancer Ther 8: 921-929, 2009.

16. Picard D: Heat shock protein 90, a chaperone for folding and regulation. Cell Mol Life Sci 59: 1640-1648, 2002.

17. Baruchello R, Simoni D, Grisolia G, Barbato G, Marchetti P, Rondanin R, Mangiola S, Giannini G, Brunetti T, Alloatti D, Gallo G, Ciacci A, Vesci L, Castorina M, Milazzo FM, Cervoni ML, Guglielmi MB, Barbarino M, Foderà R, Pisano C and Cabri W: Novel 3.4-isoxazolediamides as potent inhibitors of chaperone heat shock protein 90. J Med Chem 54: 8592-8604, 2011.

18. Jhaveri $\mathrm{K}$ and Modi S: Hsp90 inhibitors for cancer therapy and overcoming drug resistance. Adv Pharmacol 65: 471-517, 2012.

19. Patel HJ, Modi S, Chiosis G and Taldone T: Advances in the discovery and development of heat-shock protein 90 inhibitors for cancer treatment. Expert Opin Drug Discov 6: 559-587, 2011.

20. Trepel J, Mollapour M, Giaccone G and Neckers L: Targeting the dynamic Hsp90 complex in cancer. Nat Rev Cancer 10: 537-549, 2010.

21. Ramanathan RK, Egorin MJ, Eiseman JL, Ramalingam S, Friedland D, Agarwala SS Zuhowski EG, Lan J, Potter DM, Ivy SP, Ramalingam S, Brufsky AM, Wong MK, Tutchko S and Egorin MJ: Phase I and pharmacodynamic study of 17-(allylamino)-17-demethoxygenldanamycin in adult patients with refractory advanced cancers. Clin Cancer Res 13: 1769-1774, 2007.

22. Ramanathan RK, Egorin MJ, Erlichman C, Remick SC, Ramalingam SS, Naret C, Holleran JL, TenEyck CJ, Ivy SP and Belani CP: Phase I pharmacokinetic and pharmacodynamic study of 17-dimethylaminoethylamino-17-demethoxygeldanamycin, an inhibitor of heat-shock protein 90 , in patients with advanced solid tumors. J Clin Oncol 28: 1520-1526, 2010.

23. Mimnaugh EG, Chavany $C$ and Neckers L: Polyubiquitination and proteasomal degradation of the $185 \mathrm{c}$-erbB-2 receptor protein-tyrosine kinase induced by geldanamycin. J Biol Chem 271: 22796-22801, 1996.

24. Christensen JG, Schreck R, Burrows J, Kuruganti P, Chan E, Le P, Chen J, Wang X, Ruslim L, Blake R, Lipson KE, Ramphal J, Do S, Cui JJ, Cherrington JM and Mendel DB: A selective small molecule inhibitor of c-Met kinase inhibits c-Met-dependent phenotypes in vitro and exhibits cytoreductive antitumor activity in vivo. Cancer Res 63: 7345-7355, 2003.

25. Gilliland DG and Griffin JD: Role of FLT3 in leukemia. Curr Opin Hematol 9: 274-281, 2002.

26. Lopes de Menezes DE, Peng J, Garrett EN, Louie SG, Lee SH, Wiesmann M, Tang Y, Shephard L, Goldbeck C, Oei Y, Ye H, Aukerman SL and Heise C: CHIR-258: a potent inhibitor of FLT3 kinase in experimental tumor xenograft model of human acute myelogenous leukemia. Clin Cancer Res 11: 5281-5291, 2005.

27. Fathi AT and Chabner BA: FLT3 inhibition as therapy in acute myeloid leukemia: a record of trials and tribulations. Oncologist 16: 1162-1174, 2011.

28. Gottesman MM, Bates SE and Fojo T: Multidrug resistance in cancer: role of ATP-dependent transporters. Nat Rev Cancer 2: 48-58, 2002. 
29. McCollum AK, TenEyck CJ, Stensgard B, Morlan BW, Ballman KV,Jenkins RB, ToftDO and Erlichman C: P-glycoprotein mediated resistance to Hsp90-directed therapy is eclipsed by the heat shock response. Cancer Res 68: 7419-7427, 2008.

30. Banerji U, O'Donnell A, Scurr M, Pacey S, Stapleton S, Asad Y, Simmons L, Maloney A, Raynaud F, Campbell M, Walton M, Lakhani S, Kaye S, Workman P and Judson I: Phase I pharmacokinetic and pharmacodynamic study of 17-allylamino, 17-demethoxygeldanamycin in patients with advanced malignancies. J Clin Oncol 23: 4152-4161, 2005.
31. Kelland LR, Sharp SY, Rogers PM, Myers TG and Workman P. DT Diaphorase expression and tumor cell sensitivity to 17-allylamino, 17-demethoxygeldanamycin, an inhibitor of heat shock protein 90. J Natl Cancer Inst 91: 1940-1949, 1999.

32. Hostein I, Robertson D, DiStefano F, Workman $P$ and Clarke PA: Inhibition of signal transduction by the Hsp90 inhibitor 17-allylamino-17-demethoxygeldanamycin results in cytostasis and apoptosis. Cancer Res 61: 4003-4009, 2001.

33. Ellis LM and Hicklin DJ: Resistance to targeted therapies: refining anticancer therapy in the era of molecular oncology. Clin Cancer Res 15: 7471-7478, 2009. 